\title{
Permethrin Susceptibility for the Vector Culex tarsalis and a Nuisance Mosquito Aedes vexans in an Area Endemic for West Nile Virus
}

\author{
Geoffrey P. Vincent $\mathbb{D D}^{1}{ }^{1}$ Justin K. Davis $\mathbb{D}^{2},{ }^{2}$ Michael C. Wimberly $\mathbb{D}^{2}{ }^{2}$ \\ Christopher D. Carlson, ${ }^{3}$ and Michael B. Hildreth ${ }^{1,4}$ \\ ${ }^{1}$ Department of Biology and Microbiology, South Dakota State University, Brookings, SD 57007, USA \\ ${ }^{2}$ Geospatial Sciences Center of Excellence, South Dakota State University, Brookings, SD 57007, USA \\ ${ }^{3}$ South Dakota Department of Health, Public Health Laboratory, Pierre, SD 57501, USA \\ ${ }^{4}$ Department of Veterinary and Biomedical Sciences, South Dakota State University, Brookings, SD 57007, USA
}

Correspondence should be addressed to Michael B. Hildreth; michael.hildreth@sdstate.edu

Received 12 February 2018; Revised 27 May 2018; Accepted 24 June 2018; Published 11 July 2018

Academic Editor: Ademir J. Martins

Copyright ( 2018 Geoffrey P. Vincent et al. This is an open access article distributed under the Creative Commons Attribution License, which permits unrestricted use, distribution, and reproduction in any medium, provided the original work is properly cited.

\begin{abstract}
In 2016, we compared susceptibility to the insecticide, permethrin, between the West Nile virus vector, Culex tarsalis Coquillett, and a major nuisance mosquito, Aedes vexans (Meigen), using baseline diagnostic dose and time values determined using the CDC bottle bioassay protocol. Mosquitoes were collected in the wild in Brookings County, South Dakota, situated in the Northern Great Plains of the USA. The determined diagnostic dose and time were then used in 2017 to validate these measurements for the same 2 mosquito species, collected at a second location within Brookings County. The diagnostic dose was determined for multiple time periods and ranged from $27.0 \mu \mathrm{g} / \mathrm{ml}$ at $60 \mathrm{~min}$ to $38.4 \mu \mathrm{g} / \mathrm{ml}$ at $30 \mathrm{~min}$. There was no significant difference detected in mortality rates between $C x$. tarsalis and Ae. vexans for any diagnostic time and dose. For practical purposes, mosquitoes in 2017 were tested at $38 \mu \mathrm{g} / \mathrm{ml}$ for $30 \mathrm{~min}$; expected mortality rates were $93.38 \%$ for $C x$. tarsalis and $94.93 \%$ for Ae. vexans. Actual 2017 mortality rates were $92.68 \%$ for $C x$. tarsalis and $96.12 \%$ for Ae. vexans, validating the usefulness of this baseline at an additional location and year.
\end{abstract}

\section{Introduction}

Mosquito transmission of arboviruses to humans depends on multiple factors $[1,2]$, including human behavior $[3,4]$. Gujral et al. [3] suggest that human behavioral risk factors, such as the use of personal protective measures, can be influenced by the "biting pressure" created by local mosquito populations. These populations include potential vector species and nonvector nuisance mosquitoes, and the presence of many nuisance mosquitoes could increase the use of personal protectants or avoidance behavior, thereby reducing the chance of potential viral transmission by vector mosquitoes. Conversely, the lack of abundant nuisance mosquitoes may have the opposite effect. Therefore, it is important to consider nuisance as well as vector mosquitoes when developing comprehensive strategies for mosquito reduction and disease control.
Community adulticiding efforts can limit both disease and nuisance issues caused by mosquitoes, but the common use of insecticides has prompted concerns over growing resistance to insecticides in mosquito populations. Permethrin, a broad-spectrum insecticide in the pyrethroid family, is the primary adulticide used in the United States [5] and is used for agriculture to reduce crop and livestock pests $[6,7]$, as well as in residential areas to control nuisance and vector mosquito populations. Long-term usage of this class of insecticide may cause increased resistance in mosquito populations [8]. Because of its broad use and the documented cases of resistance, monitoring of permethrin resistance is important to mosquito control efforts $[9,10]$.

Most studies on insecticide resistance have focused primarily on vector mosquito species, and few have included common nuisance mosquitoes within arbovirus-endemic 
areas. Richards et al. (2017) evaluated the susceptibilities of a potential Zika virus (ZIKV) vector (Aedes albopictus (Skuse)) and 2 West Nile virus (WNV) vectors (Culex pipiens L. and Culex quinquefasciatus (Say)) to 6 different common insecticides in a study that included 26 mosquito populations from four different USA regions. They also included the treehole mosquito, Aedes triseriatus (Say), in this study, though this species is not a significant vector for Zika or WNV and is generally only a minor species in most regions. They found that the Aedes species tested were less likely to exhibit resistance when compared with Culex species, particularly for etofenprox and malathion, and found that all Aedes spp. populations tested were either susceptible or possibly resistant to permethrin while most Culex spp. populations were resistant. Given the potential role of nuisance mosquitoes in encouraging the use of personal protectants, reduction in their populations during high-risk transmission periods could lead to a reduced perceived threat of mosquito-borne diseases by the general [4] which could increase exposure to pathogens. Therefore, the susceptibility of nonvector mosquitoes to insecticides should be evaluated especially in arbovirus-endemic regions where nuisance species are far more abundant than the vector species.

In the USA Northern Great Plains, Culex tarsalis Coquillett is the primary vector for WNV, and Aedes vexans (Meigen) is generally the most predominant nuisance mosquito [11-14]. Recently, Ae. vexans has been reported as a potential vector for ZIKV [15, 16]; however, there have been no reported cases of local transmission of ZIKV in the Northern Great Plains. In eastern South Dakota, Ae. vexans populations generally swell to very large numbers in the spring and remain high during the WNV transmission season [17]. The aggressive biting of this nuisance mosquito can motivate people to use personal protection $[3,4]$. In spite of nuisance and potential public health significance of each species, we have found no studies directly comparing permethrin susceptibility for $C x$. tarsalis and Ae. vexans.

Brookings County, located in east-central South Dakota, is the fifth-most populated county and contains the fourth largest city in South Dakota, though it mostly consists of farmland. Both species of interest are abundant in this county with Ae. vexans having the largest abundance of all mosquito species. The city of Brookings has utilized a mosquito control program targeting both nuisance and vector mosquitoes, which included larviciding potential habitats and general spraying of permethrin for over 20 years, and the small cities in the county have had similar programs for over 10 years. The purpose of the present study is to compare susceptibilities of Ae. vexans and Cx. tarsalis to reagent-grade permethrin in a Center for Disease Control (CDC) bottle bioassay protocol involving multiple concentrations and time periods. For this comparison, we used adult mosquitoes freshly captured in Brookings County, an endemic area for WNV, using $\mathrm{CO}_{2}$ baited light traps. Because both species prefer to lay their eggs throughout natural habitats, harvesting and rearing $C x$. tarsalis and Ae. vexans eggs for the assay were not practical, and results can be inconsistent when rearing mosquitoes from eggs in a lab [10]. In our area, the consistent collection of $C x$. tarsalis larvae in large enough numbers to adequately compare its susceptibility to Ae. vexans was also not practical. To minimize concerns about potential high variability for data collected from wild-caught adults, the susceptibility comparisons involved a large number of mosquitoes evaluated in multiple assays conducted throughout the mosquito season. The use of field-collected mosquitoes for this comparison also allowed for testing both species together in the same bottles and testing them in the various natural physiological conditions representative of the wild populations' age distribution at any given time [18].

The data from this study were used to calculate a baseline diagnostic dose and time for permethrin susceptibility for both species that can be used in future studies for evaluating changes in permethrin resistance from this region. We have found no studies identifying values for diagnostic dose and time on permethrin susceptibility for $C x$. tarsalis and Ae. vexans, and none have been reported to the Arthropod Pesticide Resistance Database [19]. According to the CDC diagnostic dose and times should be determined for each type of insecticide used and for each species of concern within a region [20], and studies often emphasize the lack of reported diagnostic dose and times reported for Culex species, and more so with $C x$. tarsalis [21]. CDC guidelines recommend creating the diagnostic dose and time from susceptible populations; however, permethrin is used throughout the state for both agricultural and mosquito control purposes. The Center for Disease Control guidelines also recommend establishing these baselines from mosquito populations in areas where treatments are applied as a reference point for future comparisons.

\section{Methods}

2.1. Mosquito Collections. From June through August of 2016, mosquitoes were captured overnight using one CDC Miniature Light Trap Model 512 equipped with photoswitches and air-actuated gate system (John W. Hock Company, Gainesville, Florida) and baited with $\mathrm{CO}_{2}$ at a farm located $1.8 \mathrm{~km}$ from the southwestern city limits of Brookings, South Dakota $\left(44.25^{\circ},-96.81^{\circ}\right)$. Mosquitoes were collected each morning shortly after dawn. This site was selected as populations of $C x$. tarsalis and Ae. vexans are present in large enough abundances to test mortality rates for multiple permethrin concentrations. This location is also on the outskirts of a city where insecticide fogging applications targeting mosquitoes have occurred sporadically for 25 years. In June of 2017, mosquitoes were again collected using two CDC Miniature Light Traps from Oakwood State Park $\left(44.45^{\circ},-96.98^{\circ}\right)$ located $25 \mathrm{~km}$ northwest. In neither year were targeted mosquito control applications or agricultural applications of insecticide administered near either site. Mosquito species were identified based upon morphological characteristics [22].

2.2. CDC Bottle Bioassay. The CDC bottle bioassay was chosen for its effectiveness in testing field-collected mosquitoes $[23,24]$. Calibration of the CDC bottle bioassay was performed per the CDC bottle bioassay protocol [20]. These guidelines recommend that a baseline diagnostic value 
should be determined for use in comparisons for future resistance testing on specific mosquito species and geographical regions. In determining the diagnostic dose and times, we identified a concentration that would result in $100 \%$ mortality between 30 and $60 \mathrm{~min}$ and then estimated the LC98, or the lowest concentration which was lethal for $98 \%$ of mosquitoes at those time spans. For the 2016 bioassay calibration, tested concentrations were $1,10,20$, and $40 \mu \mathrm{g} / \mathrm{ml}$ of laboratory grade permethrin (Sigma-Aldrich, St. Louis, Mo.) suspended in acetone. Due to varying physiological states of wild-caught mosquitoes, replicates of each concentration were run until at least 100 mosquitoes of each species were tested, which ranged from 9 to 24 replicates depending on the availability of species at the time of the trial. Additionally, any mosquitoes that died or had physical injuries at the start of each trial, such as broken or missing wings or legs, were excluded. All trials included four treatment bottles and one negative control in which the bottle was coated with acetone only. Each test bottle was cleaned with commercial-grade detergent, rinsed thoroughly three times with tap water, and then dried in an oven at $50^{\circ} \mathrm{C}$ for 20 minutes to ensure removal of residual contaminants per the CDC bottle bioassay protocol. Control bottles were selected randomly to further ensure bottle cleaning was thorough. Each treatment consisted of clear $250 \mathrm{ml}$ bottles coated with $1 \mathrm{ml}$ of a specific concentration containing permethrin with 1 control bottle coated with $1 \mathrm{ml}$ of acetone only. For the 2017 validation bioassays, permethrin was prepared at a concentration of $38 \mu \mathrm{g} / \mathrm{ml}$ based upon the results from the 2016 calibration assay.

Prior to testing, captured mosquitoes were maintained in $30.5 \mathrm{~cm} \mathrm{X} 30.5 \mathrm{~cm}$ X $30.5 \mathrm{~cm}$ holding cages in the laboratory for 3 to 4 hours to acclimate to the environment of $23^{\circ} \mathrm{C}$ and $50 \%$ relative humidity and then removed any mosquitoes that may have died during the trapping process. Mosquitoes were transferred to the experimental bottles via a mechanical aspirator to avoid introducing condensation to the treatment bottles. The CDC bottle bioassay protocol recommended determining diagnostic times between 30 and 60 minutes so mosquito mortality was measured every $5 \mathrm{~min}$ for 60 min. Mosquitoes that would no longer right themselves after slowly rolling the bottle were considered dead. Mosquitoes that survived past $60 \mathrm{~min}$ were removed from the bottle and euthanized separately. During the 2017 bioassays, mosquitoes were only evaluated for $30 \mathrm{~min}$. Afterwards, all mosquitoes were identified to species. Only data from $C x$. tarsalis and $A e$. vexans were used in this study. Corrected mortality was not needed as no mortality occurred in any of the control bottles.

2.3. Statistical Analyses. Using mosquitoes collected in 2016, a probit model (glm function, stats package, $\mathrm{R} \times 64$ version 3.2.2) was used to model the relationship between proportion mortality (dead per total in bottle, binomial family) as a linear function of time, with slope and intercept depending on species as a factor and concentration linearly. The estimated diagnostic dose or LC98 was defined as the lowest dose for which the expected mortality exceeded the susceptibility threshold defined by the CDC ( $98 \%$ mortality) for each species and concentration at 30,45 , and $60 \mathrm{~min}[18$, 20].

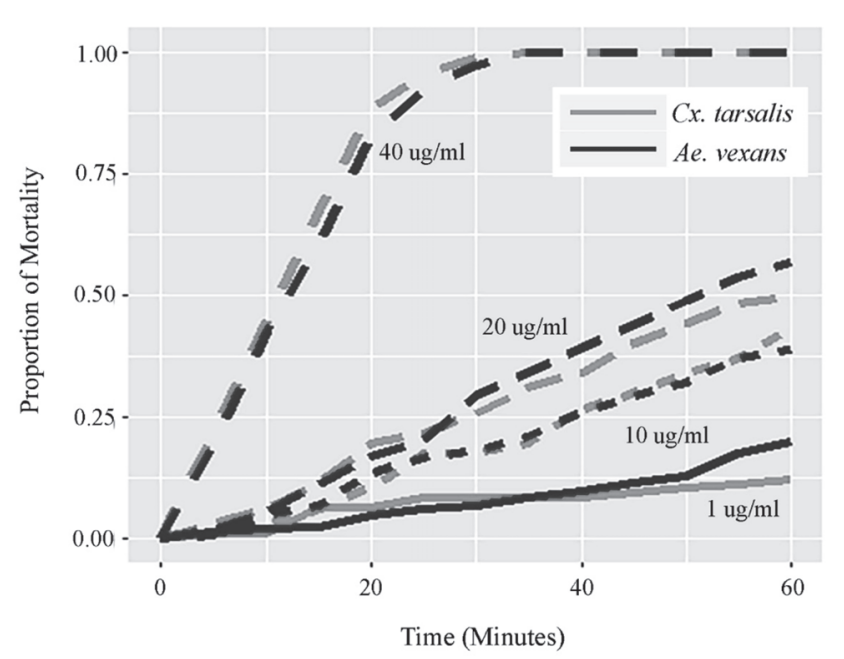

FIgURE 1: Mortality rates for $C x$. tarsalis and Ae. vexans as a function of time for various concentrations of permethrin in 2016 using probit model.

A likelihood ratio test (ANOVA function, stats package) was performed against a simpler model in which mortality depended on concentration and time but not species, to determine whether the 2 species differed by mortality in any systematic way during the experiment. For analysis of the 2017 mosquito data, 95\% exact confidence intervals were calculated for proportion mortality at the chosen dose and time (binconf function, Hmisc package) to compare with estimates obtained in 2016.

\section{Results}

Culex tarsalis $(\mathrm{n}=421)$ and Ae. vexans $(\mathrm{n}=1084)$ were tested in 2016 at various concentrations of permethrin. An additional $159 C x$. tarsalis and 207 Ae. vexans were used in control bottles containing acetone only. No mortality in the control bottles occurred during the experimental period. Observed mortality rates as functions of time, species, and permethrin concentration are displayed in Figure 1. Mortality rates increased as permethrin concentration increased and were nearly linear in time for each concentration of permethrin except for $40 \mu \mathrm{g} / \mathrm{ml}$, which reached near $100 \%$ mortality at approximately $30 \mathrm{~min}$ for both species. At 20 $\mu \mathrm{g} / \mathrm{ml}$, mortality reached $50 \%$ for both target species at 60 min.

The estimated LC98 for Ae. vexans was $38.4 \mu \mathrm{g} / \mathrm{ml}$ at 30 min and 27.0 for $60 \mathrm{~min}$. For Cx. tarsalis, it was $38.3 \mathrm{ug} / \mathrm{ml}$ at $30 \mathrm{~min}$ and $27.5 \mu \mathrm{g} / \mathrm{ml}$ at $60 \mathrm{~min}$ (Table 1). This showed that increased permethrin concentrations achieved the same mortality in less time for both species. For a given time, mortality rates are similar between the 2 species. We saw some variation after 50 minutes at $1 \mathrm{ug} / \mathrm{ml}$ where mortality rates in Ae. vexans were higher than $C x$. tarsalis, but this may have been due to one trial rapidly spiking to $70 \%$ mortality near 55 minutes (Figures 1 and 2(a)). Mortality rates at 10 $\mathrm{ug} / \mathrm{ml}$ were consistent for both species at most times with one trial reaching near $100 \%$ mortality at 60 minutes (Figures 


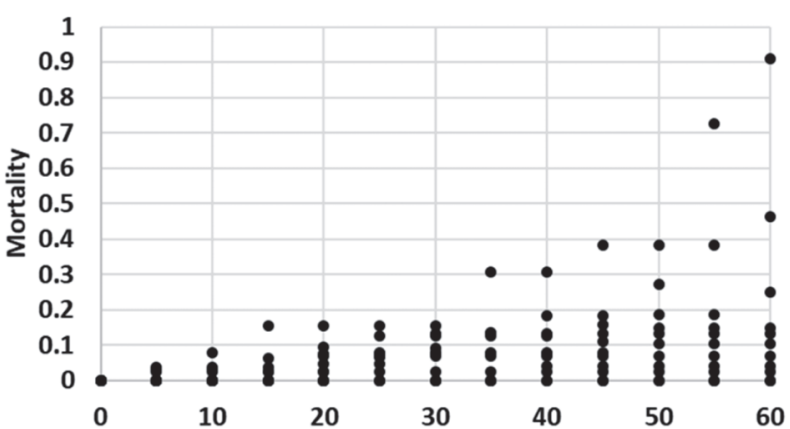

(a)

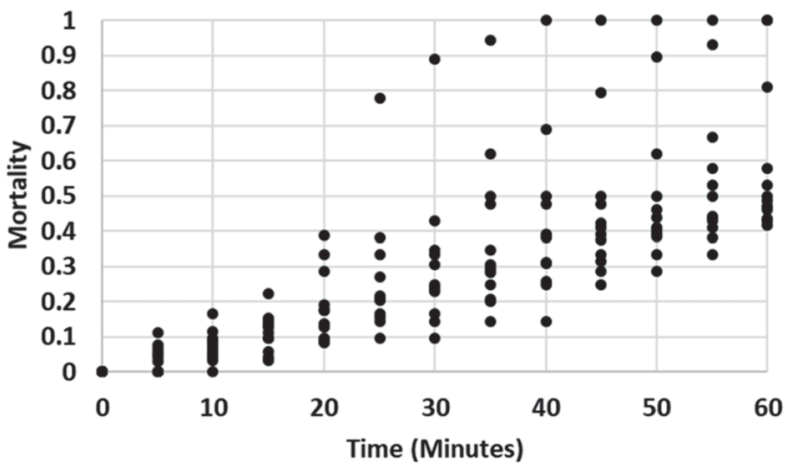

(c)

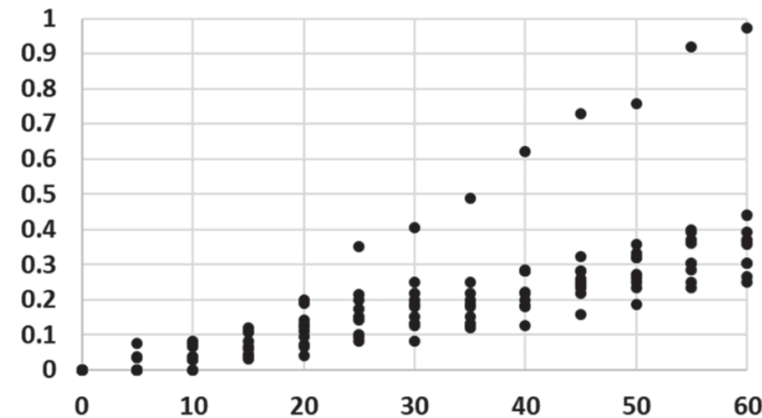

(b)

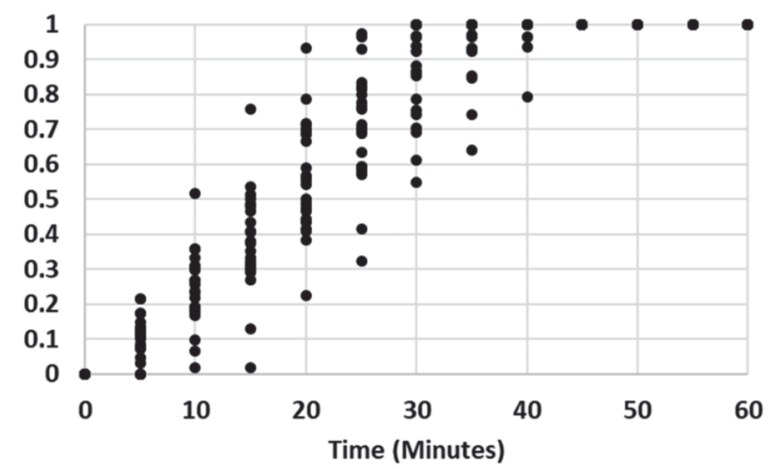

(d)

FiguRE 2: Observed mortality rates for each bottle bioassay replicate in 2016 at time intervals for $1 \mathrm{ug} / \mathrm{ml}$ (a), $10 \mathrm{ug} / \mathrm{ml}$ (b), $20 \mathrm{ug} / \mathrm{ml}$ (c), and $40 \mathrm{ug} / \mathrm{ml}(\mathrm{d})$ of permethrin.

TABle 1: LC98 diagnostic doses and times for Cx. tarsalis and Ae. vexans with lower (LCL) and upper (UCL) confidence limits.

\begin{tabular}{lcccc}
\hline Species & Time (min) & $\begin{array}{c}\text { Diagnostic } \\
\text { dose }(\mathrm{ug} / \mathrm{ml})\end{array}$ & $\begin{array}{c}\mathrm{LCL} \\
(\mathrm{ug} / \mathrm{ml})\end{array}$ & $\begin{array}{c}\mathrm{UCL} \\
(\mathrm{ug} / \mathrm{ml})\end{array}$ \\
\hline Cx. tarsalis & 30 & 38.3 & 36.9 & 40.0 \\
Ae. vexans & 30 & 38.4 & 37.0 & 40.0 \\
Cx. tarsalis & 45 & 32.1 & 30.8 & 33.6 \\
Ae. vexans & 45 & 31.8 & 30.5 & 33.3 \\
Cx. tarsalis & 60 & 27.5 & 26.3 & 28.8 \\
Ae. vexans & 60 & 27.0 & 25.9 & 28.3 \\
\hline
\end{tabular}

1 and 2(b)). Aedes vexans showed a slightly higher mortality rate at $20 \mathrm{ug} / \mathrm{ml}$ for between 30 - and 60 -minute time intervals (Figure 1) with 1 trial reaching $100 \%$ mortality at 40 minutes and a second at 60 minutes (Figure 2(c)). Mortality rates at $40 \mathrm{ug} / \mathrm{ml}$ for $C x$. tarsalis were slightly higher than $A e$. vexans at earlier times; however, both species reached $100 \%$ mortality at approximately the same time interval (Figure 1). Mortality rates reached $100 \%$ in all trials within the bioassay time limit. Using a diagnostic time longer than $30 \mathrm{~min}$ is likely inadvisable, as both species showed $100 \%$ mortality soon after that for the $40 \mu \mathrm{g} / \mathrm{ml}$ concentration (Figure 1).

A likelihood ratio test between the main model, used to calculate LC98s, and a simplified model, in which species was no longer a predictor, indicated that the mortality rates of the 2 species had statistically indistinguishable rates of mortality over concentration and time $(\mathrm{p}=0.7803)$, and any function of model estimates (such as the diagnostic dose for a given time) is unlikely to differ between the 2 species.

During the 2017 study, the estimated diagnostic doses determined in 2016 were rounded to $38 \mu \mathrm{g} / \mathrm{ml}$ for both species at 30 minutes. This dose was chosen rather than the estimated LC98s both for convenience and also at least some (approximately 1 in 20) mosquitoes should be alive at $30 \mathrm{~min}$. The mortality rates based on our model's diagnostic dose estimated mortality at 30 minutes to be $94.93 \%$ for Ae. vexans and $93.38 \%$ for Cx. tarsalis. In early 2017, 380 Ae. vexans and $123 \mathrm{Cx}$. tarsalis adult females were used to validate these calculations. Observed mortality rates for mosquitoes at the diagnostic time for Ae. vexans populations collected in 2017 at Oakwood State Park were 297/309 = 96.12\% with a 95\% exact confidence interval of 93.31 to $97.98 \%$. Mortality rates for $C x$. tarsalis collected at Oakwood State Park at the diagnostic time were $114 / 123=92.68 \%$ with $95 \%$ exact CI $(86.56,96.60 \%)$. In all cases, the $95 \%$ CI for observed mortality in 2017 contained the expected mortality rate estimated in 2016. For both species, estimated and observed mortality rates as functions of time are displayed in Figure 3.

\section{Discussion}

This study is the first direct comparison of the permethrin susceptibilities of a major vector for WNV, Cx. tarsalis, to a major nuisance mosquito, Ae. vexans, where WNV is 


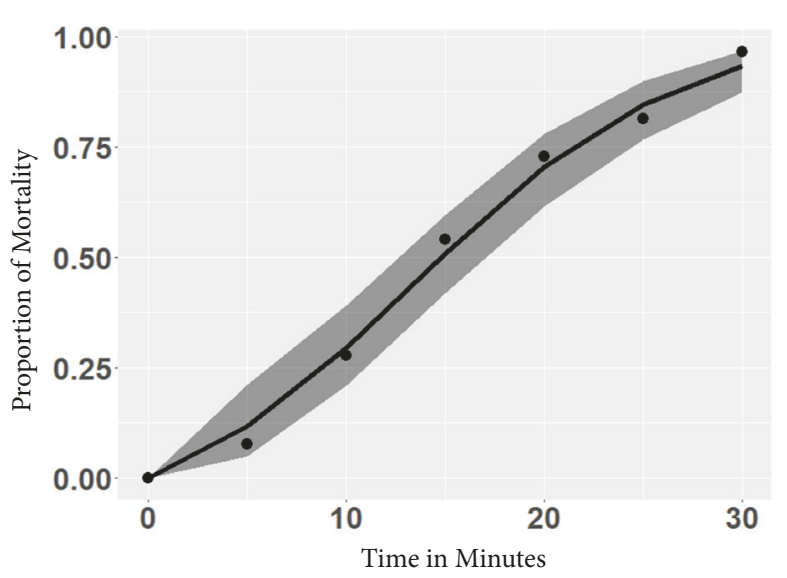

(a)

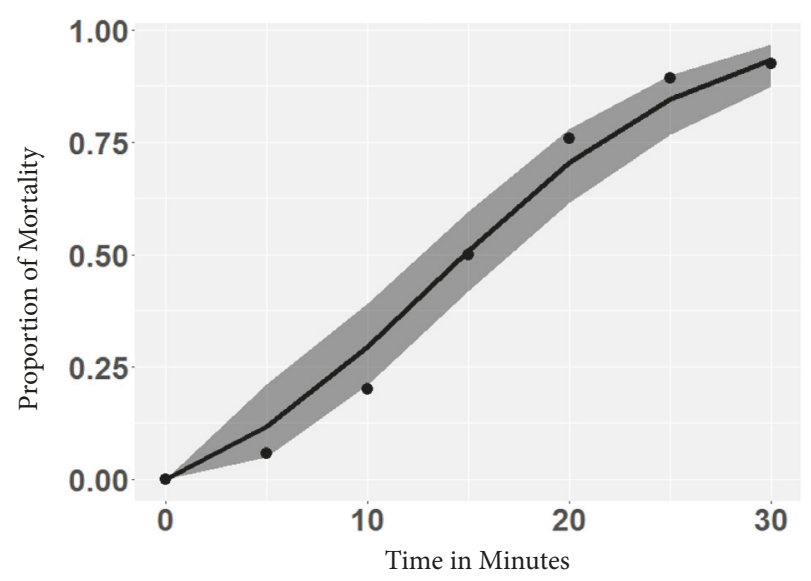

(b)

Figure 3: Bioassay mortality rates for Ae. vexans (a) and Cx. tarsalis (b) collected in 2017 (solid circles) using $38 \mu \mathrm{g} / \mathrm{ml}$ of permethrin, against estimated calibration curve (line) with 95\% confidence interval (grey shaded band) generated from data collected in 2016.

endemic to the region, and was conducted using collected adult mosquito from eastern South Dakota exposed to multiple concentrations of permethrin in a CDC bottle bioassay. Scatter-plots of the data showed that while there were some variations in individual bottles, there was good consistency in bottles for each permethrin concentration (Figure 2). The overall results showed similar mortality rates at all times for all concentrations between $C x$. tarsalis and Ae. vexans, and we found no statistical difference between the calculated mortality rates of these 2 species. Comparisons were made based upon calculated diagnostic dose and times as recommended by CDC when testing for insecticide resistance [17], and the similarities between each species were also reflected in the calculated diagnostic doses and times. The susceptibilities of $A$ e. vexans and $C x$. tarsalis remained constant between 2016 and 2017, between 2 study sites, and within and between both species. A California study used $30 \mu \mathrm{g} / \mathrm{ml}$ of permethrin and was unable to knock down $50 \%$ of their wild-caught $C x$. pipiens [25]. Richards et al. [21] found 2 Aedes spp. collected from 13 different locations within the United States that were either susceptible or possibly resistant with mortality rates ranging from $91 \%$ to $100 \%$ using $15 \mu \mathrm{g} / \mathrm{ml}$ doses at $30 \mathrm{~min}$. This same study tested 26 Cx. pipiens collected from St. Paul, Minnesota, and achieved $96 \%$ mortality using $15 \mu \mathrm{g} / \mathrm{ml}$ permethrin at $30 \mathrm{~min}$. A similar study to ours tested $49 C x$. tarsalis adults reared from field caught larva and determined a median lethal dose of $50 \mu \mathrm{g} / \mathrm{ml}$; however, they reported that this same concentration caused $100 \%$ mortality the following year and had to reduce their median lethal dose to $10 \mu \mathrm{g} / \mathrm{ml}$ [10]. A diagnostic dose and time for Ae. vexans have not been reported; however, the CDC reports that $100 \%$ mortality should occur at 30 minutes for Aedes spp. at $15 \mathrm{ug} / \mathrm{ml}$ [26]. Our study at $20 \mathrm{ug} / \mathrm{ml}$ only resulted in $25 \%$ mortality at 30 minutes for $A e$. vexans and our calculated value for $98 \%$ mortality was $38 \mu \mathrm{g} / \mathrm{ml}$ in $30 \mathrm{~min}$, over twice that of the CDC suggested guidelines. This same CDC report suggests a baseline diagnostic dose for $C x$. tarsalis as $43 \mathrm{ug} / \mathrm{ml}$ at 30 minutes. Our calculated diagnostic dose and time for Culex tarsalis were lower than the $\mathrm{CDC}$ recommendation and at $38.3 \mathrm{ug} / \mathrm{ml}$ at 30 minutes. These values indicate that $A e$. vexans in this region have become resistant to permethrin at the same level of susceptibility as $C x$. tarsalis.

Use of wild-caught adult mosquitoes in this type of bioassay is considered acceptable from both the CDC bottle bioassay protocol and the WHO test procedures for insecticide resistance, and wild-caught adult mosquitoes have been used in previous studies where mosquito aquatic stages were not consistently available $[18,20,27,28]$. Our trials were able to attain consistent results from mosquitoes with varying physiological attributes between years and geographical locations, and the results should capture the variation found in the wild. This is essential in disease control and mosquito abatement programs whose primary concern is to reduce vector and/or nuisance populations [29]. Further studies investigate variations in insecticide effectiveness between age and physiological statuses. We determined multiple options for baseline diagnostic doses and times that can be used in the Northern Great Plains. By using this method, we have a basis for comparing various species levels of susceptibility and it allows for future testing and comparisons of resistance in and between $C x$. tarsalis and Ae. vexans using the CDC bottle bioassay.

Both the vector and nuisance mosquitoes are heavily targeted within the state of South Dakota due to the former's ability to transmit WNV and the latter's overwhelmingly large abundance creating a nuisance for residents. Since nuisance mosquitoes may help motivate humans to seek shelter or use personal protection $[3,4,30]$, higher susceptibility to insecticides in nuisance mosquitoes compared to vector mosquitoes may cause mosquito control efforts to actually increase human risk for WNV. Our findings showed that the susceptibility to permethrin between the WNV vector, $C x$. tarsalis, and the nuisance mosquito, Ae. vexans, was similar in this region and that treatment will be equally effective; thus it will not diminish the nuisance mosquito more than the vector. However, the development of resistance in Ae. 
vexans should be of concern in that the control of the most abundant mosquito in the state is less effective than it should be. Considerations should be made to find more effective insecticides to control this nuisance mosquito. There is a great need for future studies to understand the level of insecticide resistance developing in vector mosquitoes throughout the United States; however, these studies should also include predominant nuisance mosquitoes in areas where both groups are abundant to ensure that susceptibility of the vectors is similar or higher so that attempts to control vector species will not have a significantly greater effect on nuisance mosquitoes, thus lowering the avoidance behaviors in humans.

\section{Data Availability}

The datasets created and analyzed during the current study are available from the corresponding author on reasonable request.

\section{Disclosure}

The contents of this publication are solely the responsibility of the authors and do not necessarily represent the official views of the Centers for Disease Control and Prevention or the Department of Health Human Services.

\section{Conflicts of Interest}

The authors declare that there are no conflicts of interest regarding the publication of this paper.

\section{Acknowledgments}

The authors would like to extend thanks to Ryan Alley, Lucas Zilverberg, Alex Macki, and Kajol Khatri for their hours in the field and lab collecting and testing mosquitoes. They would also like to thank the leadership of Oakwood State Park for allowing them to collect mosquitoes at their location. This publication was supported by Cooperative Agreement NU50CK000380 funded by the Centers for Disease Control and Prevention. This publication was also supported by grant from the NASA Applied Sciences Health and Air Quality Program (Grant no. NNX15AF74G).

\section{References}

[1] A. M. Kilpatrick, L. D. Kramer, S. R. Campbell, E. O. Alleyne, A. P. Dobson, and P. Daszak, "West Nile virus risk assessment and the bridge vector paradigm," Emerging Infectious Diseases, vol. 11, no. 3, pp. 425-429, 2005.

[2] A. M. Kilpatrick and W. J. Pape, "Predicting human West Nile virus infections with mosquito surveillance data," American Journal of Epidemiology, vol. 178, no. 5, pp. 829-835, 2013.

[3] I. B. Gujral, E. C. Zielinski-Gutierrez, A. LeBailly, and R. Nasci, "Behavioral risks for West Nile virus disease, northern Colorado, 2003," Emerging Infectious Diseases, vol. 13, no. 3, pp. 419425, 2007.
[4] E. C. Zielinski-Gutierrez and M. H. Hayden, "A model for defining West Nile virus risk perception based on ecology and proximity," EcoHealth, vol. 3, no. 1, pp. 28-34, 2006.

[5] EPA. Permethrin, Resmethrin, d-Phenothrin (Sumithrin ${ }^{\circledR}$ ): Synthetic Pyrethroids For Mosquito Control.

[6] M. A. Catangui and R. K. Berg, "Comparison of Bacillus thuringiensis corn hybrids and insecticide-treated isolines exposed to bivoltine European corn borer (Lepidoptera: Crambidae) in South Dakota.," Journal of Economic Entomology, vol. 95, no. 1, pp. 155-166, 2002.

[7] J. B. Campbell, D. J. Boxler, and R. L. Davis, "Comparative efficacy of several insecticides for control of cattle lice (Mallophaga: Trichodectidae and Anoplura: Haematopinidae)," Veterinary Parasitology, vol. 96, no. 2, pp. 155-164, 2001.

[8] M. N. Naqqash, A. Gökçe, A. Bakhsh, and M. Salim, "Insecticide resistance and its molecular basis in urban insect pests," Parasitology Research, vol. 115, no. 4, pp. 1363-1373, 2016.

[9] W. G. Brogdon and J. C. McAllister, "Insecticide resistance and vector control," Emerging Infectious Diseases, vol. 4, no. 4, pp. 605-613, 1998.

[10] A. C. Strong, B. C. Kondratieff, M. S. Doyle, and W. C. Black IV, "Resistance to permethrin in Culex tarsalis in Northeastern Colorado," Journal of the American Mosquito Control Association, vol. 24, no. 2, pp. 281-288, 2008.

[11] A. R. Barr, The Mosquitoes of Minnesota: (Diptera : Culicidae : Culicinae), University of Minnesota, Agricultural Experiment Station, 1958.

[12] E. R. Easton, R. S. Coker, and R. Ballinger, "Occurrence and seasonal incidence of mosquitoes on Indian reservations in Iowa, Nebraska and South Dakota during 1983.," Journal of the American Mosquito Control Association, vol. 2, no. 2, pp. 190195, 1986.

[13] J. A. Bell, C. M. Brewer, N. J. Mickelson, G. W. Garman, and J. A. Vaughan, "West Nile virus epizootiology, central Red River Valley, North Dakota and Minnesota, 2002-2005," Emerging Infectious Diseases, vol. 12, no. 8, pp. 1245-1247, 2006.

[14] C. M. Barker, B. G. Bolling, W. C. Black IV, C. G. Moore, and L. Eisen, "Mosquitoes and West Nile virus along a river corridor from prairie to montane habitats in Eastern Colorado," Journal of Vector Ecology, vol. 34, no. 2, pp. 276-293, 2009.

[15] A. Gendernalik, J. Weger-Lucarelli, S. M. Garcia Luna et al., "American Aedes vexans Mosquitoes are Competent Vectors of Zika Virus," The American Journal of Tropical Medicine and Hygiene, vol. 96, no. 6, pp. 1338-1340, 2017.

[16] K. L. O’Donnell, M. A. Bixby, K. J. Morin, D. S. Bradley, and J. A. Vaughan, "Potential of a northern population of Aedes vexans (Diptera: Culicidae) to transmit Zika virus," Journal of Medical Entomology, vol. 54, no. 5, pp. 1354-1359, 2017.

[17] T.-W. Chuang, M. B. Hildreth, D. L. Vanroekel, and M. C. Wimberly, "Weather and land cover influences on mosquito populations in Sioux Falls, South Dakota," Journal of Medical Entomology, vol. 48, no. 3, pp. 669-679, 2011.

[18] WHO, "Test procedures for insecticide resistance monitoring in malaria vector mosquitoes - Second edition," 2016, http://www .who.int/malaria/publications/atoz/9789241511575/en/.

[19] Database, A.A.P.R., Search: species. 2014: East Lansing, MI: Michigan State Univ.

[20] CDC. Parasites - CDC bottle bioassay. 2013.

[21] S. L. Richards, J. A. G. Balanay, M. Fields, K. Vandock, and L. Eisen, "Baseline insecticide susceptibility screening against six active ingredients for Culex and Aedes (Diptera: Culicidae) 
Mosquitoes in the United States," Journal of Medical Entomology, vol. 54, no. 3, pp. 682-695, 2017.

[22] R. F. Darsie, "Identification and geographical distribution of the mosquitos of North America," in Mosquitos of North America, R. A. Ward, Ed., Gainesville: Gainesville: University Press of Florida, north of Mexico, 2005.

[23] J. C. Mcallister, M. S. Godsey, and M. L. Scott, "Pyrethroid resistance in Aedes aegypti and Aedes albopictus from Port-auPrince, Haiti," Journal of Vector Ecology, vol. 37, no. 2, pp. 325332, 2012.

[24] D. Sun, N. Indelicato, J. Petersen, E. Williges, I. Unlu, and A. Farajollahi, "Susceptibility of field-collected mosquitoes in central New Jersey to organophosphates and a pyrethroid," Journal of the American Mosquito Control Association, vol. 30, no. 2, pp. 138-142, 2014.

[25] R. D. McAbee, K.-D. Kang, M. A. Stanich et al., "Pyrethroid tolerance in Culex pipiens pipiens var molestus from Marin County, California," Pest Management Science, vol. 60, no. 4, pp. 359-368, 2004.

[26] CDC. Insecticide Resistance. 2017 9/6/2017 5/1/2018.

[27] J.-D. Rakotoson, C. M. Fornadel, A. Belemvire et al., "Insecticide resistance status of three malaria vectors, Anopheles gambiae (s.l.), An. funestus and An. mascarensis, from the south, central and east coasts of Madagascar," Parasites \& Vectors, vol. 10, no. 1, 2017.

[28] S. Marcombe, J. Bobichon, B. Somphong et al., "Insecticide resistance status of malaria vectors in Lao PDR," PLoS ONE, vol. 12, no. 4, Article ID e0175984, 2017.

[29] W. G. Brogdon and J. C. McAllister, "Simplification of adult mosquito bioassays through use of time-mortality determinations in glass bottles," J Am Mosq Control Assoc, p. 14, 1998.

[30] R. J. Oidtman, R. C. Christofferson, Q. A. ten Bosch et al., "Pokémon Go and Exposure to Mosquito-Borne Diseases: How Not to Catch 'Em All," PLoS Currents, vol. 8, 2016. 


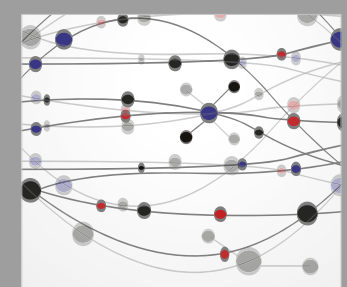

The Scientific World Journal
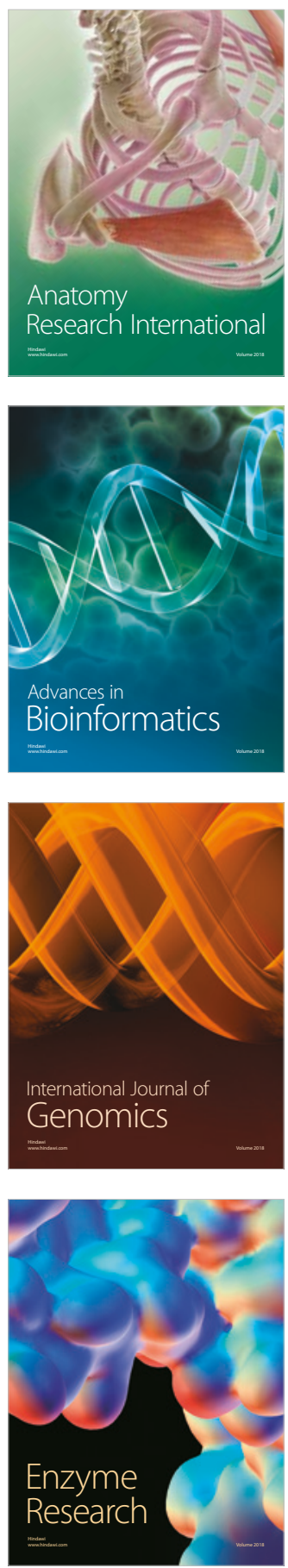
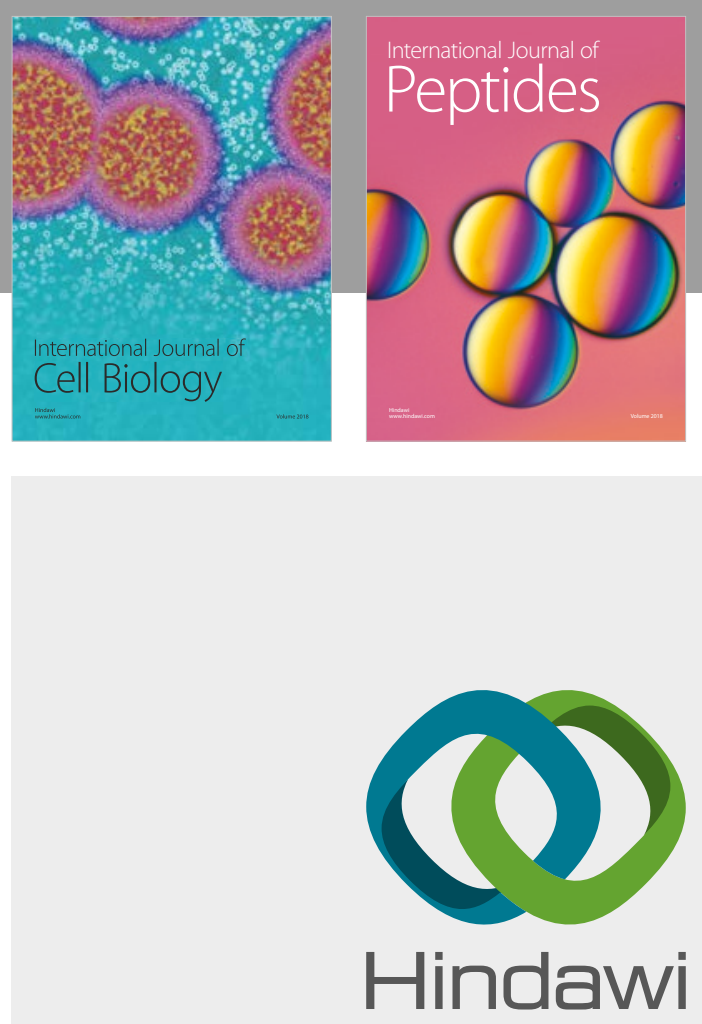

Submit your manuscripts at

www.hindawi.com
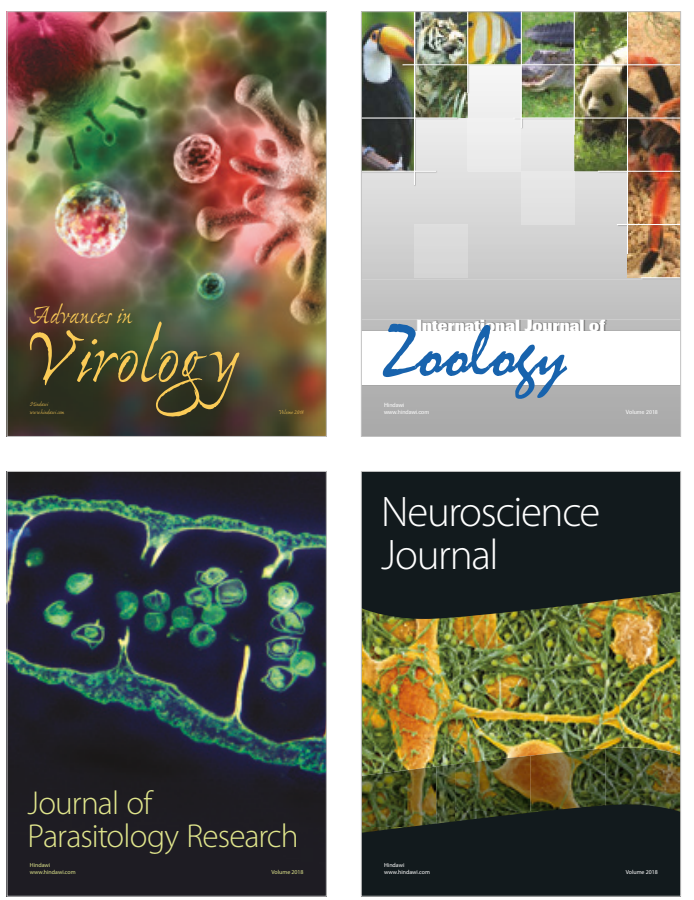
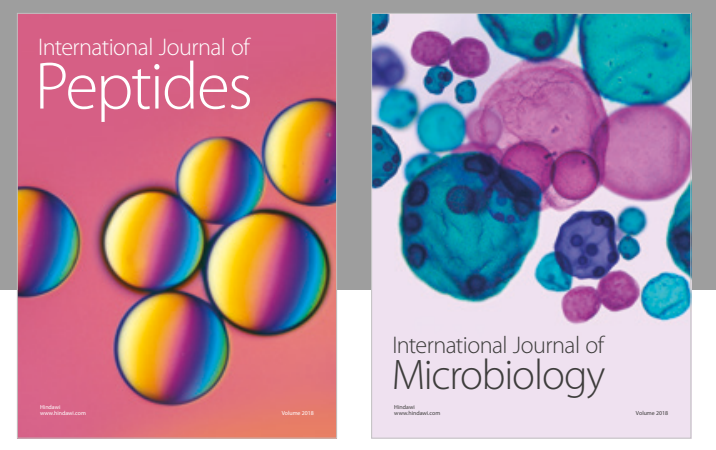

nternational Journal of Microbiology
Journal of
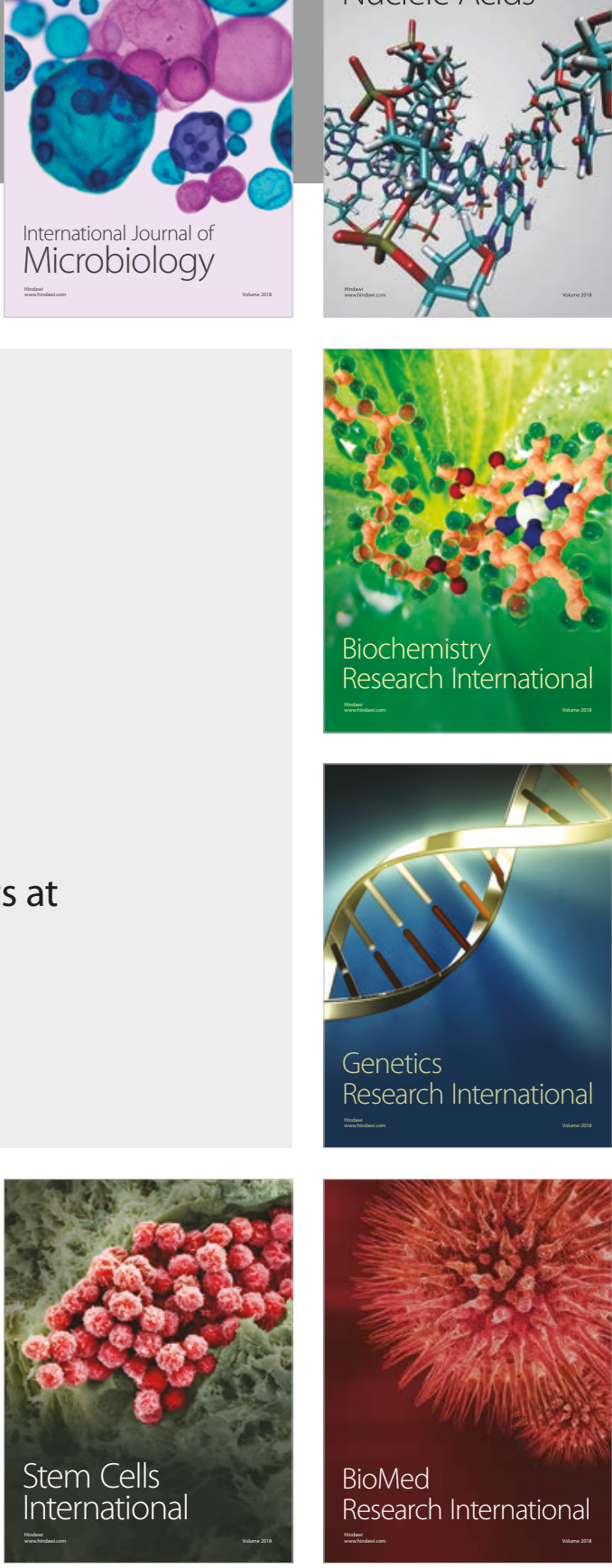
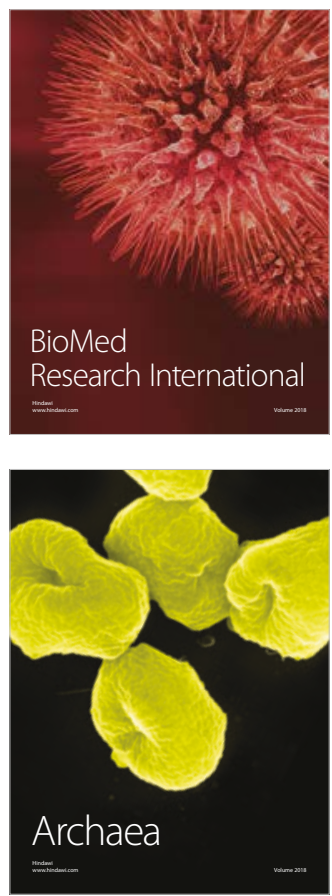